\title{
A New Activity of Doublecortin in Recognition of the Phospho-FIGQY Tyrosine in the Cytoplasmic Domain of Neurofascin
}

\author{
Krishnakumar Kizhatil, Yi-Xin Wu, Anindita Sen, and Vann Bennett \\ Howard Hughes Medical Institute and Departments of Cell Biology, Biochemistry, and Neuroscience, Duke University \\ Medical Center, Durham, North Carolina 27710
}

Doublecortin is a cytoplasmic protein mutated in the neuronal migration disorder X-linked lissencephaly. This study describes a novel activity of doublecortin in recognition of the FIGQYphosphotyrosine motif present in the cytoplasmic domain of the L1 cell adhesion molecule neurofascin. Phospho-FIGQYneurofascin (186 kDa) coimmunoprecipitated with doublecortin from detergent extracts of embryonic brain membranes, and this doublecortin-phospho-FIGQY neurofascin complex was disassociated by a synthetic phospho-FIGQY neurofascin peptide but not by a dephospho-FIGQY peptide. Doublecortin specifically recognized the phospho-FIGQY tyrosine in the context of a synthetic phospho-FIGQY neurofascin peptide and in phospho-FIGQY neurofascin isolated from cells treated with pervanadate. Mutations of doublecortin causing lissencephaly

L1 cell adhesion molecules (CAMs) are transmembrane proteins in the Ig superfamily that engage in stable protein interactions as well as signaling pathways (Brummendorf et al., 1998; Hortsch, 2000). L1 CAMs include L1, NrCAM, CHL1, and neurofascin in humans (Brummendorf et al., 1998), neuroglian in Drosophila melanogaster (Bieber et al., 1989), and LAD-1 in Caenorhabditis elegans (Chen et al., 2001). L1 CAMs have been implicated in various functions during nervous system development, including neuronal migration, neurite growth and fasciculation, synaptic plasticity, and axon guidance (Dahme et al., 1997; Brummendorf et al., 1998; Cohen et al., 1998; Demyanenko et al., 1999, 2001). Human and mouse mutations in L1 result in mental retardation, hypoplasia of the corpus callosum and corticospinal long axon tracts, and hydrocephalus (Fransen et al., 1995; Dahme et al., 1997; Cohen et al., 1998).

L1 CAM cytoplasmic domains contain a highly conserved binding site for ankyrin, a protein that provides a linkage to the spectrin-actin network (Davis and Bennett, 1993, 1994; Dubreuil et al., 1996; Hortsch, 1996; Zhang et al., 1998; Chen et al., 2001). The ankyrin-binding site in L1 CAMs includes the conserved sequence FIGQY. Phosphorylation of the FIGQY-tyrosine in response to bFGF and NGF abolishes interaction of neurofascin and ankyrin (Garver et al., 1997) and reduces neurofascin-

\footnotetext{
Received April 16, 2002; revised May 30, 2002; accepted June 17, 2002.

We thank Dr. J. Gleeson for his generous gift of the cDNA encoding human doublecortin, Dr. L. Cantley for permission to use the Scansite software program, Dr. O. Reiner for her generous gift of the antibody against DCLK, and Dr. S. M. Jenkins for providing the phospho-FIGQY antibody.

Correspondence should be addressed to Krishnakumar Kizhatil, Box 3892, Duke University Medical Center, Durham, NC 27710. E-mail: k.kizhatil@cellbio. duke.edu.

Copyright (C) 2002 Society for Neuroscience $\quad 0270-6474 / 02 / 227948-11 \$ 15.00 / 0$
}

(R59H, D62N, and G253D) abolished binding to the phosphoFIGQY peptide and to phospho-FIGQY neurofascin. Finally, phospho-FIGQY neurofascin and doublecortin colocalize in developing axon tracts and in zones enriched in migrating neurons in the embryonic cerebral cortex. In the adult rostral migratory stream, doublecortin colocalizes in migrating neurons with a phospho-FIGQY bearing L1 CAM different from neurofascin. The finding that doublecortin associates with FIGQYphosphorylated neurofascin provides the first connection of doublecortin with the plasma membrane and could be important for a function of doublecortin in directing neuronal migration.

Key words: doublecortin; phospho-FIGQY; neurofascin; $L 1$ CAM; neuronal migration; axons

mediated cell aggregation in cell culture assays (Tuvia et al., 1997). FGF receptor activity is required for phosphorylation of LAD-1 in C. elegans (Chen et al., 2001), although the protein kinase(s) directly involved in phosphorylation remains to be identified. The FIGQY/H mutation in human $\mathrm{L} 1$ results in clinical disease (Fransen et al., 1998) and abolishes ankyrin-binding activity of L1 (Needham et al., 2001) as well as neurofascin (Zhang et al., 1998). These results suggest that FIGQY-tyrosine phosphorylation and/or ankyrin-binding are essential for L1 function.

FIGQY-phosphorylated L1 CAMs have been detected in multiple tissues of vertebrates, $D$. melanogaster, and C. elegans using antibodies that recognize the phospho-FIGQY tyrosine epitope (Chen et al., 2001; Jenkins et al., 2001). Phosphorylated L1 CAMs are localized in migrating neurons and at various specialized sites of cell-cell contact, including adherens junctions in epithelial tissues, neuromuscular junctions, and paranodes of nodes of Ranvier (Chen et al., 2001; Jenkins et al., 2001). Moreover, phosphoFIGQY L1 CAMs are confined to ankyrin-free domains at the neuromuscular junction, node of Ranvier, and adherens junctions (Jenkins et al., 2001). These observations suggest the possibility that FIGQY-tyrosine phosphorylation of L1 CAMs functions as a positive signal in a signaling cascade in addition to inhibition of ankyrin-binding.

This paper presents evidence that doublecortin, a cytoplasmic protein mutated in a neuronal migration disorder [X-linked lissencephaly (XLIS)] (des Portes et al., 1998a,b; Gleeson et al., 1998), specifically associates with phospho-FIGQY neurofascin in vivo and in vitro. The finding that doublecortin associates with phospho-FIGQY neurofascin provides the first connection of 
doublecortin with the plasma membrane and could be important for a role of doublecortin in directing neuronal migration.

\section{MATERIALS AND METHODS}

cDNAs and antibodies. Plasmids encoding hemagglutinin (HA)neurofascin and HA-FIGQY/F-neurofascin have been described (Z hang et al., 1998). The cDNA encoding the full-length doublecortin (gift from J. Gleeson, University of California San Diego) and doublecortin $\mathrm{NH}_{2}$ terminus (DCN; residue 1-270) and doublecortin $\mathrm{COOH}$ terminus (DCC; residues 271-360) were inserted into pGEX6P2 (Amersham Biosciences). Doublecortin mutants were generated using the Quick Change mutagenesis kit (Stratagene). An affinity-purified anti-doublecortin antibody was generated by peptide affinity purification of serum obtained from rabbits immunized with a peptide mixture of the four peptides (amino acids 4-18, 45-60, 166-183, and 289-304 synthesized at the Howard Hughes Medical Institute peptide facility, Duke University) coupled through a cysteine residue to keyhole limpet hemocyanin (Pierce). Phospho-FIGQY antibody has been described (Jenkins et al., 2001). Additional antisera against the following proteins were used in this study: doublecortin (Santa Cruz Biotechnologies), $\beta$ III tubulin (Covance), phosphotyrosine (clone 4G10; Upstate Biotechnologies), neurofascin (Davis et al., 1996), NrCAM (Davis et al., 1996), L1 (BD Transduction), and NCAM (Chemicon).

Cell culture. B104 rat neuroblastoma cells were cultured as described (Garver et al., 1997), except that 1\% FBS was used to reduce basal FIGQY phosphorylation. Cells were transfected with cDNA encoding HA-neurofascin or FIGQY/F HA-neurofascin using Lipofectamine (Invitrogen) and then selected in $750 \mu \mathrm{g} / \mathrm{ml}$ geneticin for 2 weeks to enrich for transfected cells (Invitrogen). Subventricular zone (SVZ) explants were cultured as described (Wichterle et al., 1997) and maintained for 12 $\mathrm{hr}$ before analysis.

Fractionation of embryonic brain and immunoprecipitation. Approximately $3 \mathrm{gm}$ of embryonic rat brain was harvested in cold Leibovitz L-15 (Invitrogen) containing $0.32 \mathrm{M}$ sucrose, $2 \mathrm{~mm}$ sodium fluoride, $1 \mathrm{~mm}$ phenylarsine oxide, $1 \mathrm{~mm} \mathrm{Na} \mathrm{VO}_{4}, 1 \mathrm{~mm}$ PMSF, $1 \mathrm{~mm}$ 4-(2aminomethyl)benzenesulfonylfluoride hydrochloride (AEBSF), and 10 $\mu \mathrm{g} / \mathrm{ml}$ leupeptin. Brains were homogenized in $4 \mathrm{vol}$ of buffer containing $100 \mathrm{~mm}$ PIPES, $50 \mathrm{~mm}$ HEPES, $100 \mathrm{~mm} \mathrm{NaCl}, 1 \mathrm{~mm}$ NaEDTA, $1 \mathrm{~mm}$ magnesium sulfate, $1 \mathrm{~mm}$ ATP, $0.32 \mathrm{~m}$ sucrose, $1 \mathrm{~mm} \mathrm{NaF}, 1 \mathrm{~mm}$ AEBSF, $10 \mu \mathrm{g} / \mathrm{ml}$ leupeptin, $10 \mu \mathrm{g} / \mathrm{ml}$ pepstatin, and $1 \mathrm{~mm} \mathrm{Na}_{3} \mathrm{VO}_{4}$, $\mathrm{pH}$ 6.9. The homogenate was centrifuged at $100 \times g$ to remove the nuclei. The postnuclear supernatant was centrifuged at $20,000 \times g$, and the pellet was extracted with homogenization buffer containing $1 \%$ Triton X-100 (extraction buffer) for $30 \mathrm{~min}$ on ice to solubilize membrane proteins. The supernatant from the $20,000 \times g$ spin was subjected to a $100,000 \times g$ spin for $1 \mathrm{hr}$. The supernatant from this step was designated the cytosolic fraction. Immunoprecipitation was performed by incubating $10 \mu \mathrm{g}$ of rabbit anti-doublecortin with $2 \mathrm{ml}$ of Triton X-100 extract of membranes followed by addition of Protein A Sepharose beads. The Sepharose was then washed five times with extraction buffer and extracted with SDS for electrophoresis.

Isolation of recombinant doublecortin. Glutathione $S$-transferase (GST)doublecortin fusion proteins were affinity purified using glutathione Sepharose beads and released from the beads using Precision protease ( $80 \mathrm{U}$ ), which cleaves the polypeptide chain between the GST moiety and doublecortin. Proteins were further purified by gel filtration chromatography on a Superose 12 column to obtain monodisperse preparations with full-length doublecortin eluting at a $V_{\mathrm{e}} / V_{\mathrm{o}}$ of $1.5, \mathrm{DCN}$ at a $V_{\mathrm{e}} / V_{\mathrm{o}}$ of 1.74 , and DCC at a $V_{\mathrm{e}} / V_{\mathrm{o}}$ of 1.84. Concentrations of purified doublecortin, DCN, and DCC were estimated on the basis of the extinction coefficients of $0.5,0.6$, and 0.15 , respectively, which were derived from the amino acid sequence. Wild-type doublecortin protein and mutated doublecortin protein preparations were affinity purified using glutathione Sepharose beads and centrifuged at $100,000 \times g$ for $45 \mathrm{~min}$ after enzymatic removal of the GST tag to remove aggregated protein.

In vitro doublecortin-phospho-FIGQY peptide binding assay. Synthetic peptides (18-mer) KQFNEDGSFIGQpYTVRKD, KQFNEDGSFIGQYTVRKD, and KQFNEDGSFIGQFTVRKD bearing biotin conjugated to the $\mathrm{NH}_{2}$-terminal lysine were immobilized on streptavidincoated wells (Pierce). The wells were blocked with $3 \% \mathrm{w} / \mathrm{v}$ BSA in PBS. Purified doublecortin (400 nM) was added to the wells after removal of the blocking solution and incubated overnight at $4^{\circ} \mathrm{C}$. Wells were washed with PBS with $0.1 \%$ Tween 20 . Binding was detected using doublecortin antibodies and secondary antibodies conjugated to alkaline phosphatase
(AP). AP activity was detected using the colorimetric substrate $p$-nitrophenol (absorbance at $405 \mathrm{~nm}$ ).

In vitro doublecortin-native phospho-FIGQY neurofascin binding assay. B104 cells, enriched for the expression of exogenous HA-neurofascin or FIGQY/F HA-neurofascin by a 2 week selection in geneticin $(750 \mu \mathrm{g} /$ $\mathrm{ml}$ ), were incubated in the presence and absence of $100 \mu \mathrm{M}$ sodium pervanadate for $45 \mathrm{~min}$ (Garver et al., 1997). Cells were harvested in 50 mm Tris- $\mathrm{Cl}, \mathrm{pH} 7.5,0.5 \%$ deoxycholate, $1.0 \%$ NP40, $1.0 \%$ Triton X-100, $300 \mathrm{~mm} \mathrm{NaCl}, 1 \mathrm{~mm}$ Na-EDTA, PMSF (200 $\mu \mathrm{g} / \mathrm{ml})$, AEBSF (2 mm), leupeptin, and pepstatin $(10 \mu \mathrm{g} / \mathrm{ml})$, dephostatin $(50 \mu \mathrm{M}), \mathrm{Na}_{3} \mathrm{VO}_{4}(1.0$ $\mathrm{mm})$, and $\mathrm{NaF}(1.0 \mathrm{~mm})$ (lysis buffer). The lysate was cleared by centrifugation at 100,000 $\times g$ and incubated with HA 11 antibody (Covance) followed by the addition of Protein G Sepharose beads. The beads containing immunoaffinity-purified neurofascin were washed five times with lysis buffer and incubated with blocking buffer. Purified doublecortin (400 nM) in $10 \mathrm{~mm}$ sodium phosphate buffer, $\mathrm{pH} 7.4,150 \mathrm{~mm} \mathrm{NaCl}$, $1 \mathrm{~mm}$ NaEDTA, $0.2 \%$ BSA, 5\% sucrose, $0.1 \%$ Triton $\mathrm{X}-100$, and $1 \mathrm{~mm}$ $\mathrm{NaN}_{3}$ (binding buffer) was added to immobilized neurofascin. The beads were washed three times with PBS containing $0.2 \% \mathrm{v} / \mathrm{v}$ Tween 20 . The washed Sepharose beads were then treated with $20 \mu \mathrm{l}$ of $2 \mathrm{~mm}$ HA peptide (Covance) solution to elute bound neurofascin and doublecortin. Eluates were subjected to SDS-PAGE and immunoblotting as described (Garver et al., 1997). The primary antibodies were detected using ${ }^{125} \mathrm{I}-$ labeled protein A/G and quantitated by Image Quant software (Molecular Dynamics) after phosphorimaging.

Immunocytochemistry. Immunocytochemistry was performed on 10$\mu \mathrm{m}$-thick frozen sections of adult rat brain from animals perfused with $2 \%$ paraformaldehyde and from whole embyros (Davis et al., 1996). For immunofluorescence of SVZ explant-cultures, the cells were fixed with $3 \%$ paraformaldehyde and then incubated with $10 \%$ horse serum (Sig$\mathrm{ma}$ ), $1 \% \mathrm{BSA}$, and $0.5 \% \mathrm{v} / \mathrm{v}$ Triton $\mathrm{X}-100$ for $3 \mathrm{hr}$. The cultures were incubated with primary antibodies overnight at $4{ }^{\circ} \mathrm{C}$ (Wichterle et al., 1997). Antibodies were used at the following concentrations: antiphospho-FIGQY $(0.8 \mu \mathrm{g} / \mathrm{ml})$, goat anti-doublecortin $(2 \mu \mathrm{g} / \mathrm{ml})$, anti- $\beta \mathrm{III}$ tubulin $(2 \mu \mathrm{g} / \mathrm{ml})$, anti-neurofascin $(1 \mu \mathrm{g} / \mathrm{ml})$, and the anti-doublecortinlike kinase (DCLK) (1:50 dilution of stock). Secondary antibodies donkey anti-rabbit TRITC $(1: 400 \mathrm{v} / \mathrm{v})$, donkey anti-mouse FITC $(1: 400 \mathrm{v} / \mathrm{v})$, and donkey anti-goat Cy5 (1:400 v/v) were obtained from Jackson ImmunoResearch Labs (West Grove, PA). After treatment with appropriate secondary antibodies (Jackson ImmunoResearch Labs), images were obtained by laser scanning confocal microscopy using a water immersion 40 power 1.2 numerical aperture objective.

\section{RESULTS}

\section{Doublecortin binds directly to a phospho-FIGQY synthetic peptide derived from the cytoplasmic domain of neurofascin}

Doublecortin was identified as a candidate phospho-FIGQY binding protein by screening a rat fetal brain phage expression library with a biotinylated 30-mer synthetic peptide containing the phospho-FIGQY motif (KDSLVDpYGEGGEGQFNEDGSFIGQpYTVRKD) derived from the cytoplasmic domain of neurofascin (data not shown). Doublecortin has a closely related homolog on chromosome 13 (DC13) that encodes for alternatively spliced forms that include a doublecortin-like protein, and a doublecortin domain fused to a protein kinase domain (Burgess et al., 1999). DC13 potentially could also interact with phosphoFIGQY peptides. However, this study has focused on doublecortin because of its clinical significance and the availability of doublecortin mutations with characterized phenotypes.

A doublecortin-phospho-FIGQY motif interaction was evaluated by ELISA using $\mathrm{NH}_{2}$-terminally biotinylated peptides immobilized on streptavidin-coated wells of a 96-well plastic plate (see Materials and Methods). Purified recombinant doublecortin (see Materials and Methods) was incubated with a biotinylated phospho-FIGQY peptide (QFNEDGSFIGQpYTVRKD) derived from the cytoplasmic domain of neurofascin as well as equivalent peptides that either were not phosphorylated on the FIGQY tyrosine or had phenylalanine substituted for tyrosine 
A

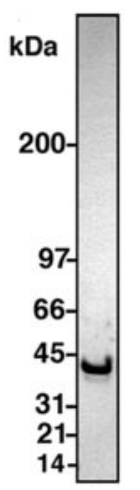

C

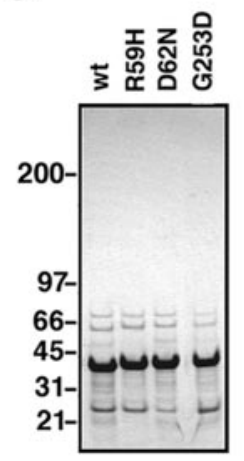

B

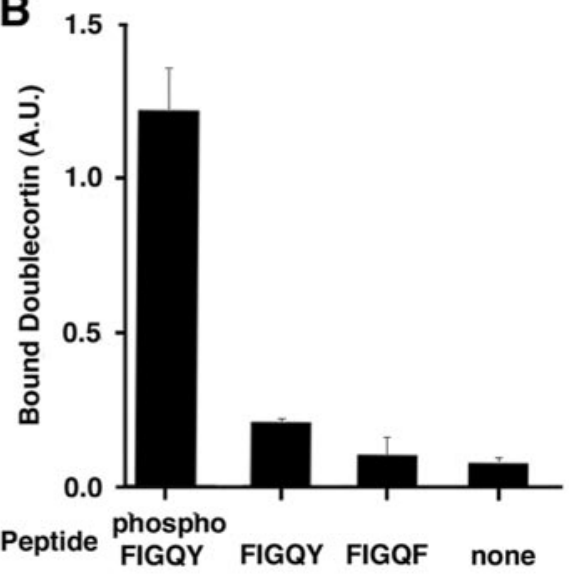

D

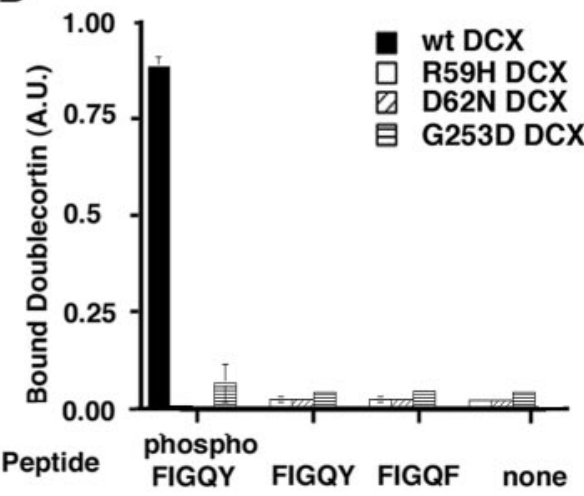

Figure 1. Doublecortin binds directly to a synthetic peptide bearing the phospho-FIGQY motif, and mutations in doublecortin that cause $\mathrm{X}$-linked lissencephaly abolish the doublecortin-phospho-FIGQY motif interaction. $A$, Coomassie blue-stained gel of purified monodisperse recombinant doublecortin $(2 \mu \mathrm{g})$. $B$, Results of a representative peptidebinding assay. The $y$-axis of the graph represents the doublecortin binding to the synthetic peptides in arbitrary units (A.U.) and was obtained as described in Materials and Methods. $C$, Coomassie blue-stained gel of partially purified recombinant doublecortin and doublecortin mutants: R59H, D62N, and G253D. D, Results of a representative peptide-binding assay. The $y$-axis of the graph represents in arbitrary units the doublecortin binding to the synthetic peptides. Black bars represent binding for wild-type doublecortin, white bars represent binding for $\mathrm{R} 59 \mathrm{H}$ doublecortin, diagonally striped bars represent binding for D62N doublecortin, and horizontally striped bars represent binding for G253D doublecortin. In $B$ and $D$, the peptides used are listed below each bar representing doublecortin binding, phospho-FIGQY, FIGQY, FIGQF, or no peptide.

(FIGQY/F). A Coomassie blue-stained SDS-PAGE gel of the purified monodisperse recombinant doublecortin revealed a single polypeptide band of $\sim 40 \mathrm{kDa}$ (Fig. $1 A$ ). The phosphoFIGQY-bearing peptide elicited a doublecortin-binding signal that was 12-fold over nonspecific binding (Fig. 1B). A similar increase in signal was observed in two other experiments. Doublecortin did not show significant binding to either the nonphosphorylated FIGQY peptide or the FIGQF peptide, as indicated by lack of increase in signal over nonspecific binding of doublecortin to the wells.

\section{Doublecortin mutations that cause lissencephaly abolish binding to the phospho-FIGQY neurofascin peptide}

We next determined the effect of mutations of doublecortin that cause lissencephaly on the ability of doublecortin to bind to the

phospho-FIGQY neurofascin peptide. Doublecortin mutations cluster within two repeated domains in the $\mathrm{NH}_{2}$-terminal domain (Sapir et al., 2000; Taylor et al., 2000). Mutations R59H and $\mathrm{D} 62 \mathrm{~N}$ are located in the first repeat domain, and G253D is located in the second repeat domain. Wild-type and mutated recombinant doublecortin polypeptides were isolated using GSTaffinity chromatography, the GST-protein domain was removed and without further purification (see Materials and Methods), resolved on a Coomassie blue-stained gel (Fig. 1C). Wild-type doublecortin binds the phospho-FIGQY peptide but not FIGQY or FIGQF peptides (Fig. 1D, black bar). All three mutants failed to bind specifically to the phospho-FIGQY peptide, with no significant increase in signal over background binding and binding to peptides lacking the FIGQY phospho-tyrosine. This result indicates that at least three of the currently mapped mutations in doublecortin that cause disease abolish the direct binding of doublecortin to the phospho-FIGQY neurofascin peptide.

\section{Phospho-FIGQY neurofascin coimmunoprecipitates with doublecortin from embryonic brain extracts}

An in vivo interaction between doublecortin and phosphoFIGQY L1 CAMs was evaluated by immunoprecipitating doublecortin from Triton X-100 extracts of embryonic day (E) 18 rat brain membranes under nondenaturing conditions and then immunoblotting immunoprecipitated proteins with an affinitypurified anti-phospho-FIGQY antibody (Jenkins et al., 2001). E18 rat brain was selected because of the high expression of doublecortin at the equivalent embryonic age of E16.5 in mouse (Francis et al., 1999), as well as high expression of phosphoFIGQY L1 CAMs (Jenkins et al., 2001). Twenty-five percent of the cellular doublecortin is associated with the particulate fraction (Fig. 2A, $M$ ), suggesting that a fraction of doublecortin may be attached to membranes.

A $186 \mathrm{kDa}$ phospho-FIGQY L1 CAM coimmunoprecipitated with antibody against doublecortin, whereas neither doublecortin (Fig. 2B, bottom panel) nor phospho-FIGQY L1 CAM was immunoprecipitated with nonspecific rabbit IgG. Heat treatment of the Triton X-100 brain membrane extracts to $55^{\circ} \mathrm{C}$ abolished the phospho-FIGQY L1 CAM-doublecortin interaction (Fig. 2B, right panel). These results indicate that a doublecortin $186 \mathrm{kDa}$ phospho-FIGQY L1 CAM complex exists in vivo and requires native folding for one or both of these proteins. In contrast, NCAM, a cell adhesion molecule prominently expressed in embryonic brain (Fig. 2C, Tot) that does not belong to the L1 family and lacks the FIGQY motif in its cytoplasmic domain, does not coimmunoprecipitate with doublecortin (Fig. 2C).

The identity of the phospho-FIGQY L1 CAM that coimmunoprecipitated with doublecortin was evaluated using antibodies against neurofascin, L1, and NrCAM (Fig. 2D). The extent of enrichment of each of these proteins in the immunoprecipitated fraction was determined by measuring blot intensity of polypeptides in the immunoprecipitate and an equivalent volume of the total membrane extract. Neurofascin is enriched sevenfold in the doublecortin immunoprecipitate (Fig. 2D, compare neurofascin Tot, DCX IP). L1, although detectable in immunoprecipitates (Fig. 2D, L1 DCX IP), is not enriched relative to the starting extract. NrCAM, although evident in the total extract (Fig. 2D, $\mathrm{NrCAM}$ Tot) is not coimmunoprecipitated (Fig. 2D, $\mathrm{NrCAM}$ $D C X I P)$. Similar results were obtained in two other experiments. These data indicate that neurofascin is a major L1 CAM coimmunoprecipitating with doublecortin from E18 brain extracts. CHL1 was not evaluated and could also be present. 
A
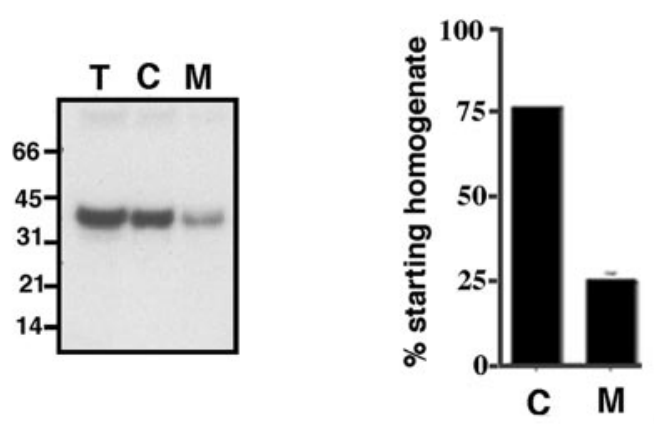

B

Pre IP

treatment:

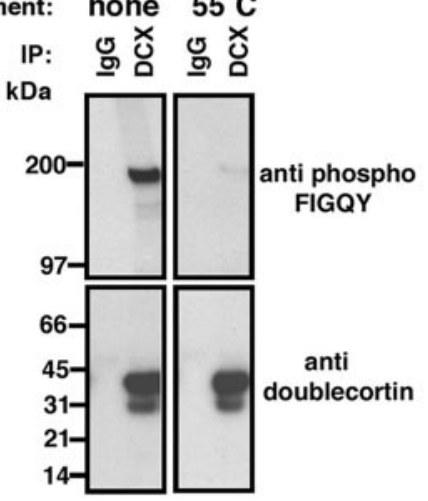

C

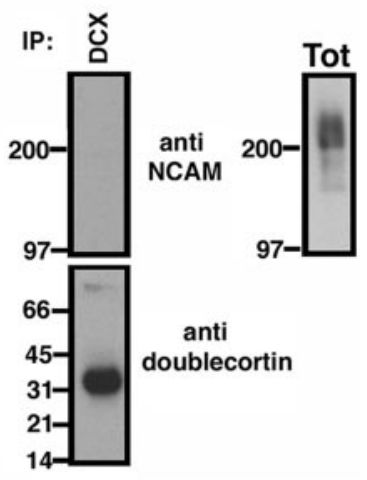

D
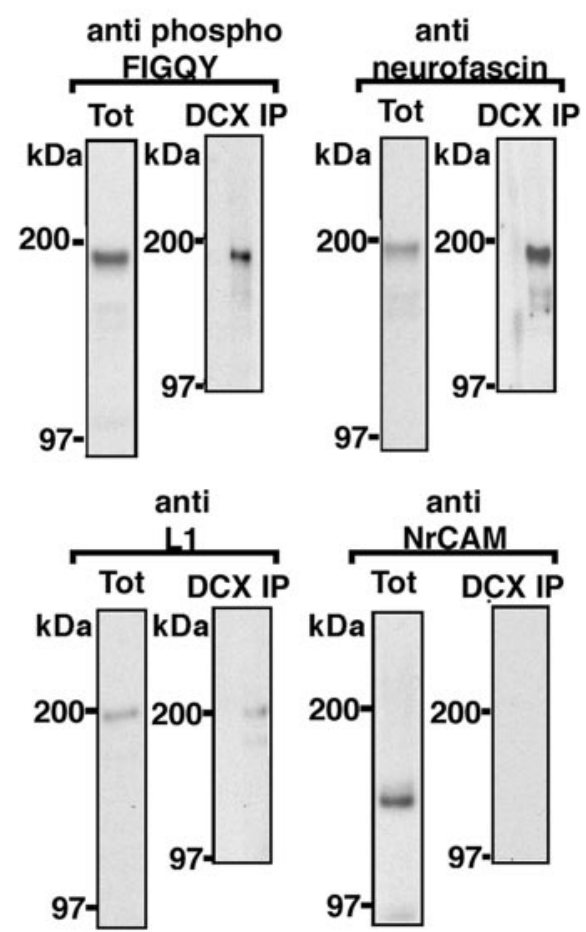

Figure 2. Doublecortin and phospho-FIGQY L1 CAMs form a complex in embryonic rat brain. A, Left panel, Immunoblot of equivalent volumes $(10 \mu \mathrm{l})$ of total embryonic brain homogenate $(T)$, cytosolic fraction $(C)$, and Triton X-100 extract of membrane fraction $(M)$ with a rabbit polyclonal doublecortin antibody. Right panel, Doublecortin in the different fractions (see Materials and Methods) is represented as a percentage of the amount in the starting homogenate $(T) . B$, Immunoblot analysis of immunoprecipitates obtained using doublecortin antibodies from Triton

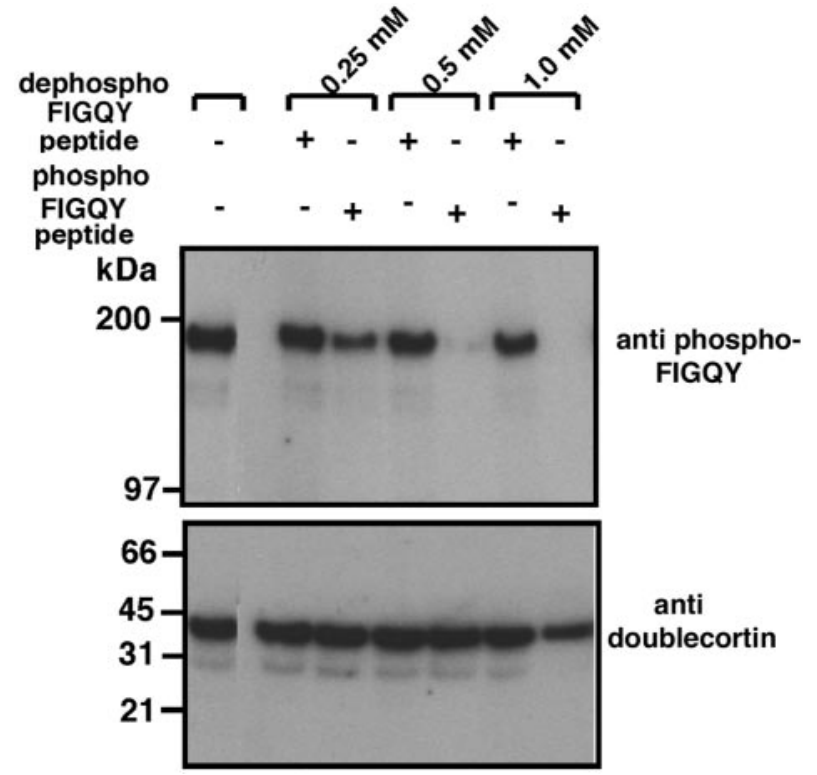

Figure 3. Doublecortin-phospho-FIGQY L1 CAM complex in embryonic brain membranes is disrupted by a phospho-FIGQY synthetic peptide but not a dephospho-FIGQY peptide. Shown is immunoblot analysis of immunoprecipitated polypeptides obtained using antibody against doublecortin (Fig. 2) after preincubation of Triton X-100 lysate with synthetic peptides containing either the phospho-FIGQY or the FIGQY motif. The amount and nature of the synthetic peptide used are indicated above the blot. Antibodies used for the immunoblot are shown to the right of the blot.

We next showed that the in vivo association of neurofascin with doublecortin is mediated through the phospho-FIGQY motif. The addition of increasing concentrations of the phosphoFIGQY neurofascin peptide (NEDGSFIGQpYTVRKD) to the Triton X-100 brain membrane lysate before immunoprecipitation of doublecortin resulted in reduction $(0.25 \mathrm{~mm}$ peptide) and $>90 \%$ elimination $(0.5 \mathrm{~mm}$ peptide) of the $186 \mathrm{kDa}$ phosphoFIGQY neurofascin that coimmunoprecipitated with doublecortin (Fig. 3). In contrast, the unphosphorylated FIGQY peptide at $0.5 \mathrm{~mm}$ had no effect on coimmunoprecipitation of phosphoFIGQY L1 CAM with doublecortin. Comparable levels of doublecortin were immunoprecipitated in the presence and absence of the peptides.

\section{Doublecortin binds to phospho-FIGQY neurofascin in vitro}

We next studied the doublecortin interaction with the phosphoFIGQY motif in the context of full-length neurofascin. Purified recombinant doublecortin (Fig. $1 A$ ) was tested for the ability to bind neurofascin bearing an $\mathrm{NH}_{2}$-terminal HA-peptide (HAneurofascin) that was FIGQY tyrosine phosphorylated, unphos-

$\leftarrow$

X-100 membrane lysates (Materials and Methods). Antibodies used in immunoprecipitation are shown at the top of the blots. Antibodies used for immunobloting are shown on the right-hand side of the blots. $D C X$, Doublecortin; IP, immunoprecipitation. $C$, Immunoblot analysis of immunoprecipitates obtained using doublecortin antibody as well as total Triton X-100 membrane lysate with anti-NCAM antibody. $D$, Immunoblot analysis of immunoprecipitates obtained using doublecortin antibody as well as total Triton X-100 membrane lysate with antibodies against neurofascin, L1, and NrCAM. The antibody used for immunoblot is shown on the top of the blots. Tot, Triton X-100 membrane lysate; DCX $I P$, doublecortin immunoprecipitate. 
A

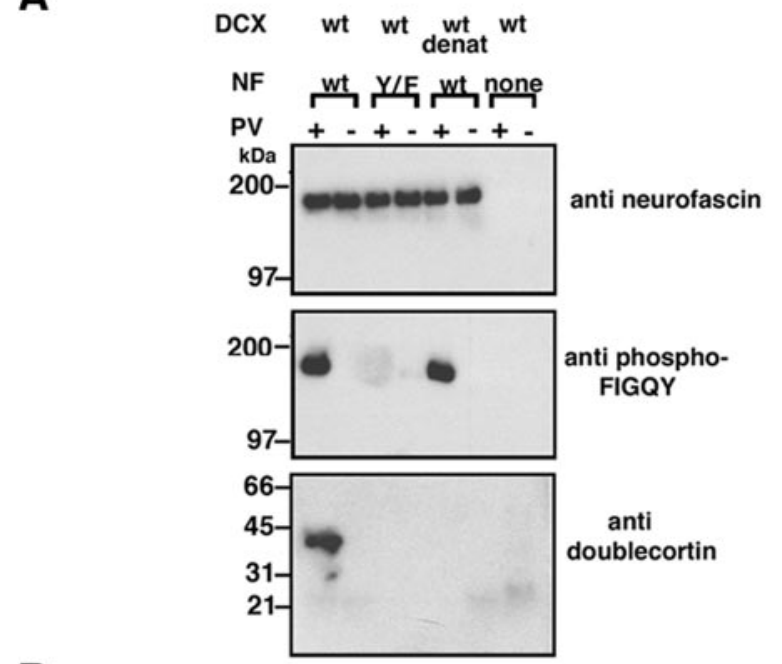

B

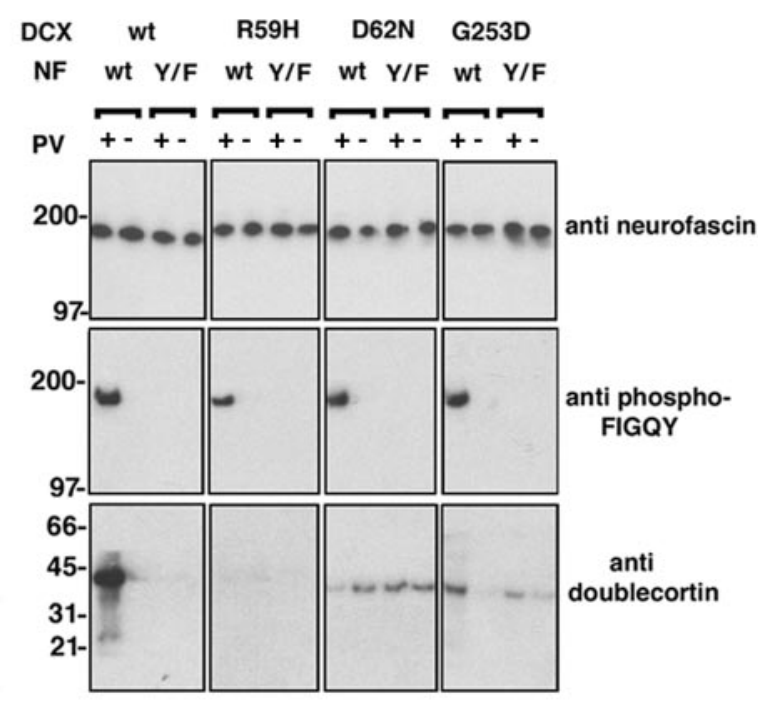

C

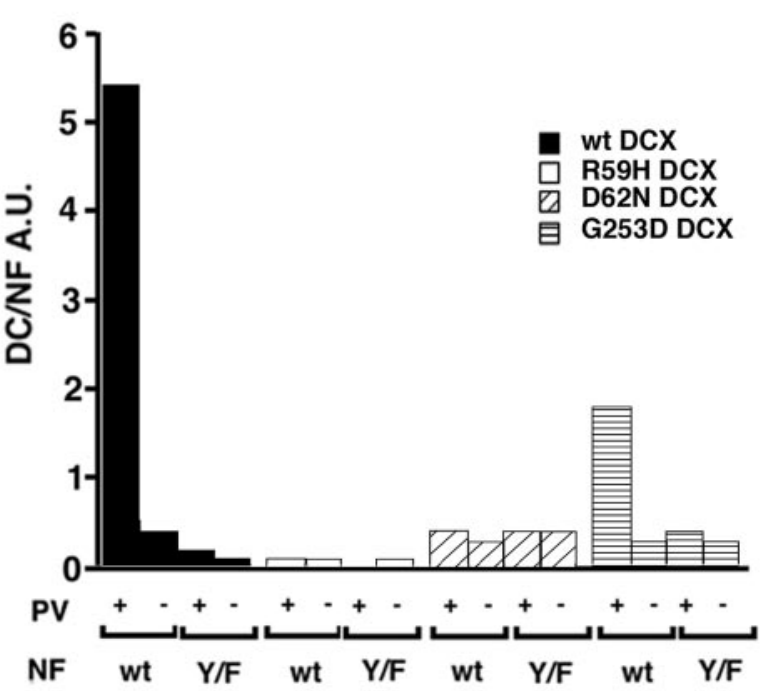

Figure 4. Doublecortin binds directly to FIGQY tyrosine-phoshorylated full-length neurofascin. $A$, Phospho-FIGQY native neurofascin binds doublecortin in the in vitro binding assay (Materials and Methods). $B$, Mutants of doublecortin that cause neuronal migration defects do not bind to full-length neurofascin. In $A$ and $B$, the antibodies used for immunoblotting are shown to the right of the blots. The doublecortin phorylated, or with phenylalanine substituted for tyrosine (FIGQY/F). HA-neurofascin polypeptides were isolated from cell extracts and immobilized on Protein G Sepharose using an anti-HA antibody (see Materials and Methods). FIGQY tyrosine phosphorylation was achieved by treating the cells with the tyrosine phosphatase inhibitor, sodium pervanadate, before immunoisolation of neurofascin (Garver et al., 1997). Neurofascindoublecortin complexes were specifically eluted from the immune complex using HA peptide and analyzed with (1) anti-neurofascin antibody to confirm neurofascin expression, (2) anti-phosphoFIGQY antibody to confirm phosphorylation of neurofascin, and (3) anti-doublecortin antibody to evaluate doublecortin binding. The blots in Figure $4 A$ are arranged with anti-neurofascin blots on top, the anti-phospho-FIGQY L1 CAM blots in the middle, and the anti-doublecortin blots at the bottom. The top blot shows that equivalent amounts of wild-type and FIGQY/F mutant neurofascin polypeptides were used in the binding assay. No detectable neurofascin was immunoprecipitated in the absence of anti-HA antibodies (Fig. 4A, none). Doublecortin is present only in samples containing phospho-FIGQY neurofascin; no doublecortin could be detected in the absence of the phosphoFIGQY tyrosine with wild-type neurofascin from untreated cells and FIGQY/F mutant neurofascin from either pervanadatetreated or untreated cells. In addition, heat-denatured doublecortin (Fig. 4A, wt denat) failed to bind to phospho-FIGQY neurofascin, indicating that an intact properly folded structure of doublecortin was necessary for the interaction. This assay demonstrates a direct interaction between native neurofascin and doublecortin dependent on the phospho-FIGQY tyrosine.

Doublecortin mutations that result in neuronal migration defects and block recognition of phospho-FIGQY peptides (Fig. 2) also disrupt binding to phospho-FIGQY neurofascin. The blots in Figure $4 B$ are arranged as in Figure $4 A$. The first set of blots confirms that wild-type doublecortin prepared without gel filtration binds (Fig. 1C) phospho-FIGQY neurofascin but not dephospho-FIGQY neurofascin or FIGQY/F neurofascin. The next three sets of blots show that mutated doublecortin polypeptides (Fig. 1C) fail to specifically bind phospho-FIGQY neurofascin. ${ }^{125}$ I-signals representing immunoreactive doublecortin were normalized with respect to the amount of neurofascin signal and are presented in bar graphs (Fig. 4C). Wild-type doublecortin binds phospho-FIGQY neurofascin with an $\sim 10$-fold higher efficiency than unphosphorylated or FIGQY/F neurofascin (Fig. 4C,

\footnotetext{
$\leftarrow$

proteins used are shown above each of the four columns of blots. In $A$ and $B$, pervanadate treatment of the B104 cells transfected with HA-tagged neurofascin before immunoprecipitation is indicated by + , and the lack of treatment is indicated by - above the blots. The type of neurofascin is indicated above the blots in $A$ and $B: w t$, wild type; $Y / F$, FIGQY/F neurofascin. In $A$, none indicates nonspecific mouse $\mathrm{IgG}$ used instead of anti-HA antibody. In $A$, wild-type purified doublecortin was used in all binding sets as indicated above the blots; wt denat refers to heat-denatured wild-type doublecortin. In $B$ the identities of doublecortin proteins used are shown above each of the four columns of blots. $C$, Graphical representation of the results of the binding assay shown in $B$. The $y$-axis represents in arbitrary units the ratio of doublecortin signal to the neurofascin signal after background correction. The neurofascin used in the binding is shown below the $x$-axis. $w t$, Wild type; $Y / F$, FIGQY/F neurofascin. Pervanadate treatment or lack of it is indicated by + or - , respectively. Black bars represent binding for wild-type doublecortin, white bars represent binding for $\mathrm{R} 59 \mathrm{H}$ doublecortin, diagonally striped bars represent binding for D62N doublecortin, and horizontally striped bars represent binding for G253D doublecortin. DCX, Doublecortin; NF, neurofascin; $P V$, pervanadate.
} 
A
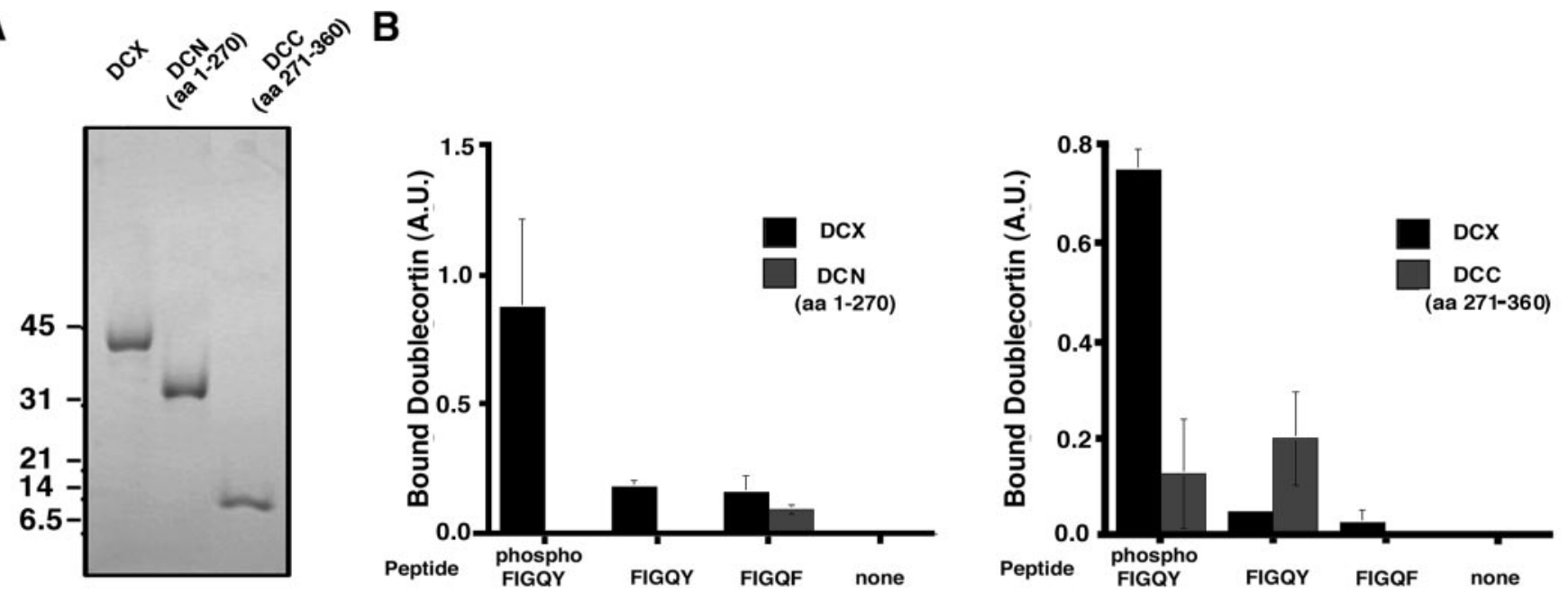

C
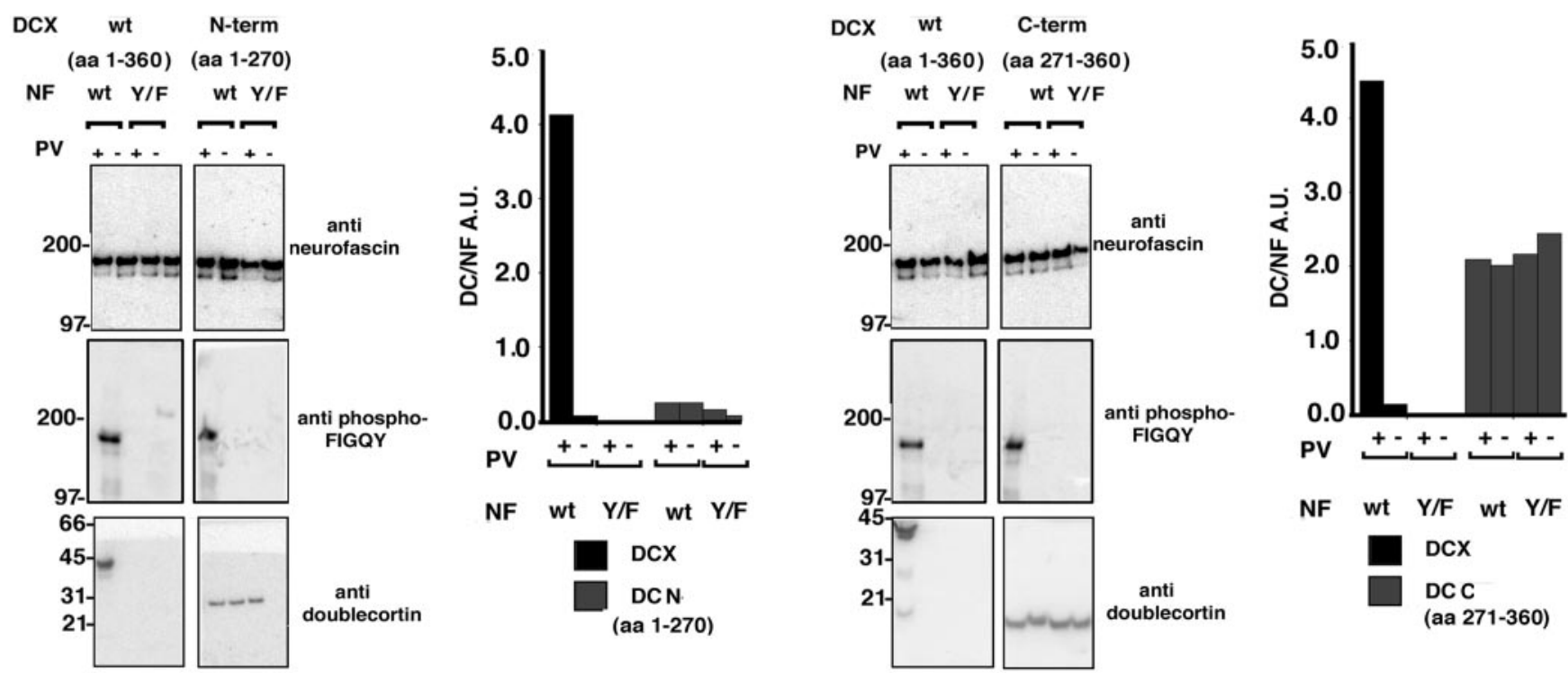

Figure 5. Individual domains of doublecortin fail to bind the phospho-FIGQY motif. $A$, Coomassie blue-stained gel of purified monodisperse recombinant doublecortin, DCN domain, and DCC domains. $B$, Peptide binding assay. The graph on the left shows the result of assay testing the ability of the DCN domain to bind peptides bearing the phospho-FIGQY motif. Black bars, Doublecortin; gray bars, DCN domain. The graph on the right shows the result of assay testing the ability of the DCC domain to bind peptides bearing the phospho-FIGQY motif. Black bars, Doublecortin; gray bars, DCC domain. Binding is represented as arbitrary units. The peptides used are listed below each bar representing doublecortin binding. $C$, Binding of native doublecortin and DCN domain to immunoisolated native neurofascin was performed as described (Materials and Methods). The antibodies used for immunoblotting are shown to the right of the blots. The graphical representation of the binding is shown to the right of the blots also. D, Binding of native doublecortin and DCC domain to immunoisolated native neurofascin was performed as described in Materials and Methods. The antibodies used for immunoblotting are shown to the right of the blots. In $C$ and $D$, the neurofascin used in the binding is also indicated above the blot. wt, Wild type; $Y / F$, FIGQY/F neurofascin. Pervanadate treatment or lack of it is indicated by + or - , respectively. $D C X$, Doublecortin; $N F$, neurofascin; $P V$, pervanadate. The $y$-axis represents in arbitrary units the ratio of doublecortin signal to the neurofascin signal after background correction. Black bars, Full-length doublecortin; gray bars, doublecortin domains DCN in $C$ and DCC in $D$.

black bars). In marked contrast, R59H and D62N mutated doublecortin polypeptides fail to bind phospho-FIGQY neurofascin (Fig. 4C, white and diagonally striped bars). The G253D mutant binds fivefold less efficiently than wild-type doublecortin to phospho-FIGQY neurofascin in this experiment (Fig. 4C, horizontally striped bars). The binding of mutant doublecortin to unphosphorylated neurofascin is nonspecific, because this binding is observed when the mutant proteins are heat denatured. These results demonstrate that clinically relevant doublecortin mutations abolish or reduce binding of doublecortin to phosphoFIGQY neurofascin.

\section{Interaction with the phospho-FIGQY motif requires the full-length doublecortin protein}

$\mathrm{NH}_{2}$-terminal sequencing of polypeptides produced by limited proteolysis of purified doublecortin with trypsin, chymotrypsin, and V8 protease revealed two independently folded proteaseresistant domains composed of amino acids 45-270 and amino 
A

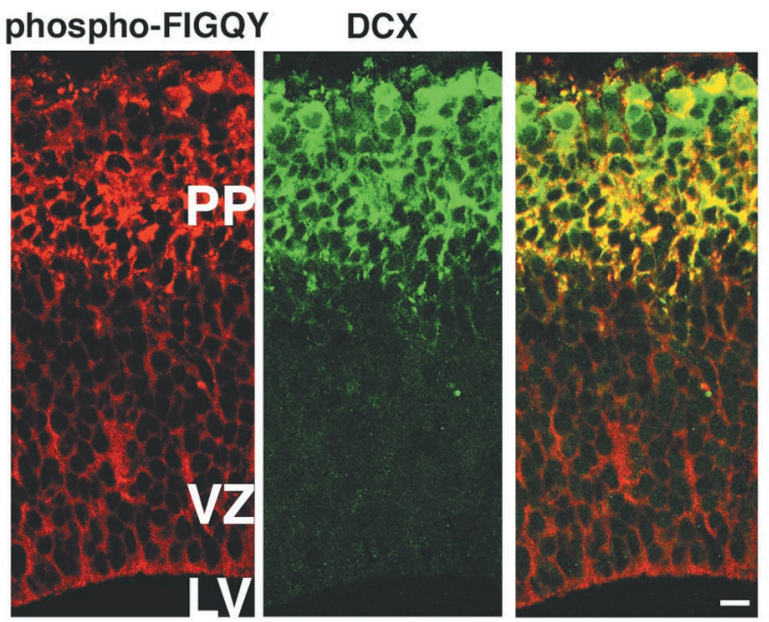

B

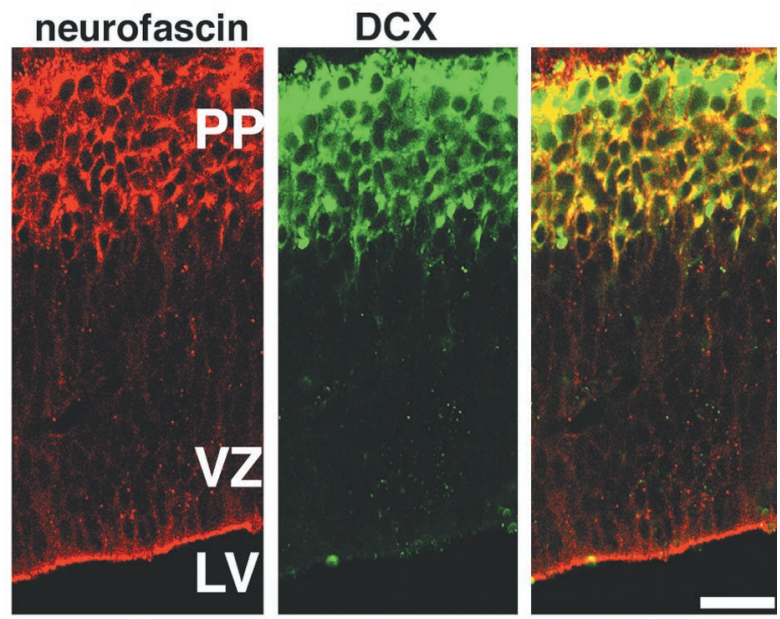

C

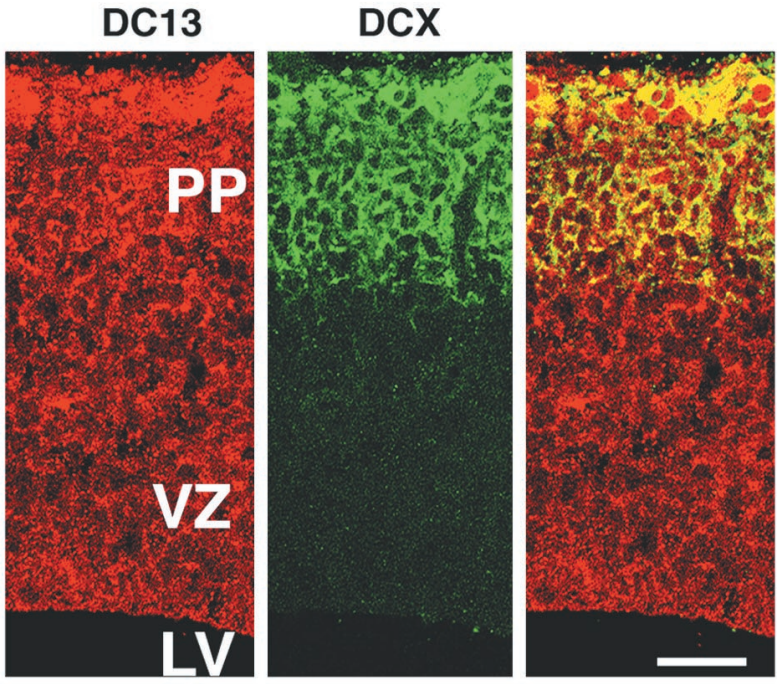

Figure 6. Migrating neurons coexpress phospho-FIGQY L1 CAMs and doublecortin in embryonic brain. $A$, Double immunofluorescence staining of a parasagittal section of E15 rat brain with anti-phospho-FIGQY antibody and goat anti-doublecortin (Materials and Methods): phosphoFIGQY L1 CAMs (red, left), doublecortin ( green, middle), and overlay (right). Scale bar, $10 \mu \mathrm{m}$. B, Double immunofluorescence labeling of a parasagittal section of E15 rat brain with rabbit anti-neurofascin antibody and goat anti-doublecortin: neurofascin (red, left), doublecortin (green, acids 271-360 (our unpublished data). These experimentally determined domain boundaries are in agreement with boundaries predicted from sequence analysis by other groups by the analysis of the doublecortin amino acid sequence (Sapir et al., 1997; Taylor et al., 2000). Doublecortin domains were expressed as recombinant proteins (see Materials and Methods), DCN encompassing the first 270 amino acids of doublecortin and, thus the experimentally determined N-terminal domain of doublecortin plus the first 45 amino acids, and the DCC encompassing the C-terminal domain of doublecortin. A Coomassie blue-stained gel of the purified proteins after removal of the GST fusion protein is shown (Fig. $5 A$ ). The ability of these domains to bind the phospho-FIGQY motif in the context of a synthetic peptide (Fig. $5 B$ ) as well as native neurofascin protein (Fig. 5C,D) was tested. In the peptide-binding assay, only the full-length doublecortin, but not the individual DCN and DCC domains, was capable of binding the phospho-FIGQY-bearing peptide. Similar results were obtained in the native phospho-neurofascin binding assay performed as in Figure 3. The blots in Figure 5, $C$ and $D$, are arranged with anti-neurofascin blots on top, the anti-phosphoFIGQY L1 CAM blots in the middle, and the anti-doublecortin blots at the bottom. The individual domains DCN and DCC failed to show an increase in binding to phospho-FIGQY neurofascin compared with unphosphorylated FIGQY neurofascin and FIGQY/F neurofascin, in contrast to the full-length doublecortin (Fig. 5, $C$ and D, compare black and gray bars above $w t N F$ in the presence and absence of $P V$ ). The binding of DCN and DCC to unphosphorylated neurofascin is nonspecific because such a binding to neurofascin is observed even when the recombinant DCN and DCC proteins were heat denatured. These results indicate that the doublecortin-binding site for phosphoFIGQY neurofascin requires collaboration of at least two domains.

\section{Doublecortin and phospho-FIGQY L1 CAMs colocalize in migrating neurons and in tracts of developing axons}

The sites of coexpression of doublecortin and phospho-FIGQY neurofascin were determined by immunofluorescence of sections of embryonic rat brain. In the E15 rat cerebral cortex, the first wave of postmitotic neurons have migrated from the neuroepithelial germinal zone lining the ventricles of the brain and have settled in a region called the preplate below the pial surface. Continued neuronal migration eventually splits the preplate to form the six-layered cortical plate. The anti-phospho-FIGQY antibody shows a preference for phospho-FIGQY neurofascin but also recognizes other FIGQY tyrosine-phosphorylated L1 CAMs (Jenkins et al., 2001). Figure $6 A$ shows double-immunofluorescence labeling of the E15 embryonic rat brain sections for phospho-FIGQY L1 CAMs and for doublecortin. The pial surface of the brain is at the top of the panel, and the lateral ventricle is at the bottom of the panel. Phospho-FIGQY L1 CAM (red, left panel) expression is enriched in the preplate zone and colocalizes with doublecortin (green, middle panel), which is expressed only in postmitotic neurons (Francis et al., 1999; Gleeson et al., 1999) within this zone. Colocalization seen as regions of yellow representing the overlap of red and green staining of phospho-FIGQY

middle), and overlay (right). Scale bar, $25 \mu \mathrm{m}$. C, Double immunofluorescence labeling of a parasagittal section of E15 rat brain with rabbit antidoublecortin-13 antibody and goat anti-doublecortin: doublecortin-13 (red, left), doublecortin (green, middle), and overlay (right). Scale bar, $25 \mu \mathrm{m}$. 
A

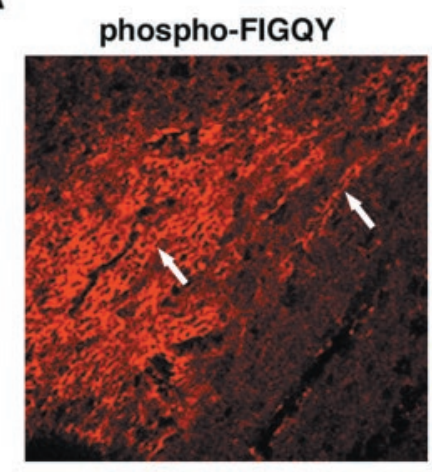

B

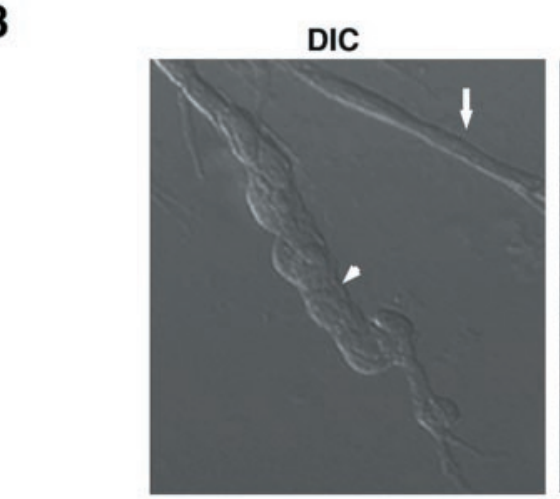

phospho-FIGQY
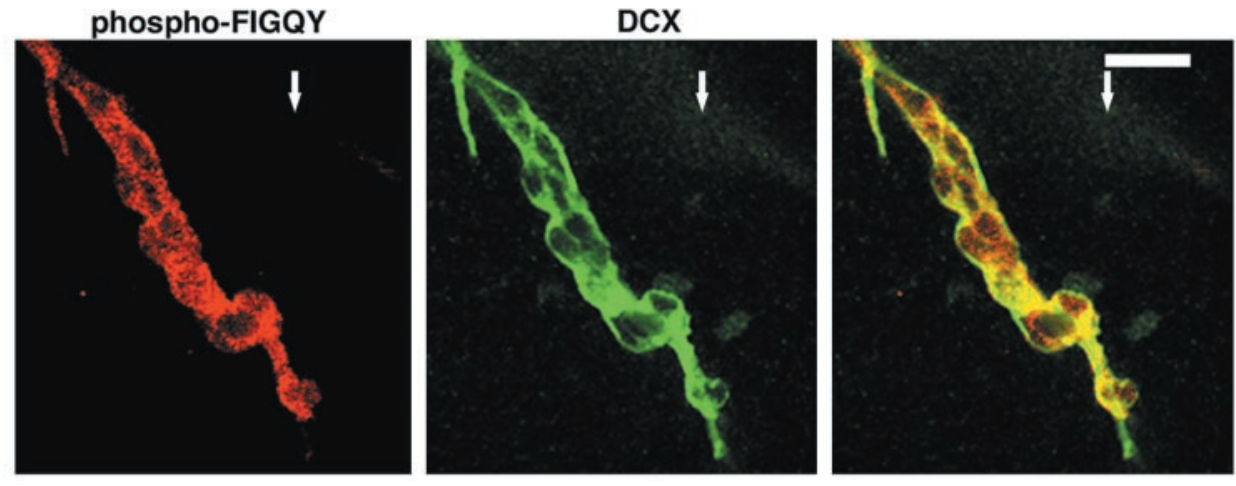

Figure 7. Migrating neurons in the rostral migratory stream coexpress phospho-FIGQY L1 CAMs and doublecortin in the adult brain. $A$, Doublecortin and phospho-FIGQY L1 CAMs are coexpressed in migrating neurons of the rostral migratory stream in adult brain. Shown is double immunofluorescence labeling of a parasagittal section of the rostral cortex of adult rat brain using rabbit anti-phospho-FIGQY antibody and goat anti-doublecortin: phospho-FIGQY L1 CAM (red, left), doublecortin (green, middle), and overlay (right). Arrows indicate the chain-like structures formed by the migrating neurons. Scale bar, $50 \mu \mathrm{m}$. $B$, Doublecortin and phospho-FIGQY L1 CAMs are coexpressed in primary cultures of SVZ neurons. Cultures (Materials and Methods) were subjected to immunofluorescence with anti-phospho-FIGQY L1 CAM antibody, goat anti-doublecortin, and monoclonal anti- $\beta$ III tubulin. Top panels show the DIC image (left) and $\beta$ III tubulin (right); bottom panels show phospho-FIGQY L1 CAM (red, left), doublecortin (green, middle), and overlay (right). $\beta$ III tubulin-positive chain migrating neurons (arrowheads): nonneuronal process as indicated by the lack of $\beta$ III tubulin (arrow). Scale bar, $25 \mu \mathrm{m}$. antibody and the doublecortin antibody, respectively, is shown in Figure $6 A$ (right panel). The anti-phospho-FIGQY antibody also reacts with cells in the ventricular zone. Doubleimmunofluorescence labeling of E15 rat brain sections for neurofascin (Fig. 6B, red, left panel) and doublecortin (Fig. 6B, green, middle panel) shows that the two proteins are coexpressed in cells within the preplate at this embryonic age (Fig. 6B, yellow, right panel). L1 expression was not observed in the cerebral cortex at this stage of development (data not shown). This is in line with the finding that L1 expression in developing rat brain is first observed at E17 (Fukuda et al., 1997). NrCAM expression was also not seen at E15 cortex (data not shown). These results indicate that neurofascin is the major FIGQY tyrosinephosphorylated L1 CAM coexpressed with doublecortin in the E15 cerebral cortex. CHL1 was not evaluated and could also be present.

Double labeling for doublecortin and DC13, the autosomal doublecortin homolog, is shown in Figure $6 C$. The pattern of labeling of phospho-FIGQY L1 CAMs (Fig. 6A) is similar to localization of DC13 (Fig. 6C, red, left panel) (Lin et al., 2000).
Efforts to test the interaction of the phospho-FIGQY L1 CAMs with the closely related DC13 protein failed because DC13 antibodies available to us failed to immunoprecipitate DC13.

In adult rats, neuroblasts from the SVZ migrate along the rostral migratory stream to renew the neuronal population within the olfactory bulb (Lois and Alvarez-Buylla, 1994; Lois et al., 1996). Sections of the rostral cerebral cortex including the SVZ and olfactory bulb were triple labeled with the rabbit polyclonal phospho-FIGQY antibody, the goat polyclonal doublecortin antibody, and $\beta$ III tubulin monoclonal antibody (Fig. 7A). The phospho-FIGQY antibody labels (red, left panel) cells in this region of continued neurogenesis and neuronal migration in chain-like patterns (arrows) (Jenkins et al., 2001). These chainlike structures express $\beta$ III tubulin (data not shown), a protein expressed in postmitotic neurons (Lee et al., 1990). These chainlike structures are also labeled with antibody against doublecortin as reported previously ( green, middle panel) (Gleeson et al., 1999; Nacher et al., 2001). The colocalization of signals representing phospho-FIGQY and doublecortin within the chain-like migrating neurons is seen as yellow in the right panel. The chain-like 
phospho-FIGQY
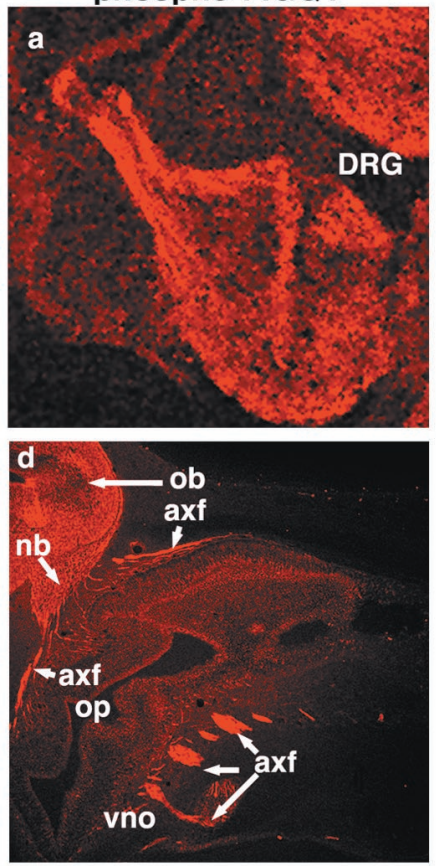

9

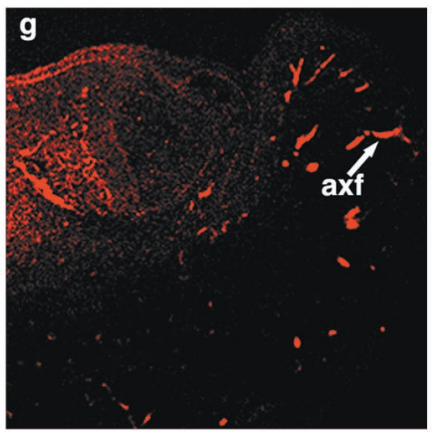

DCX
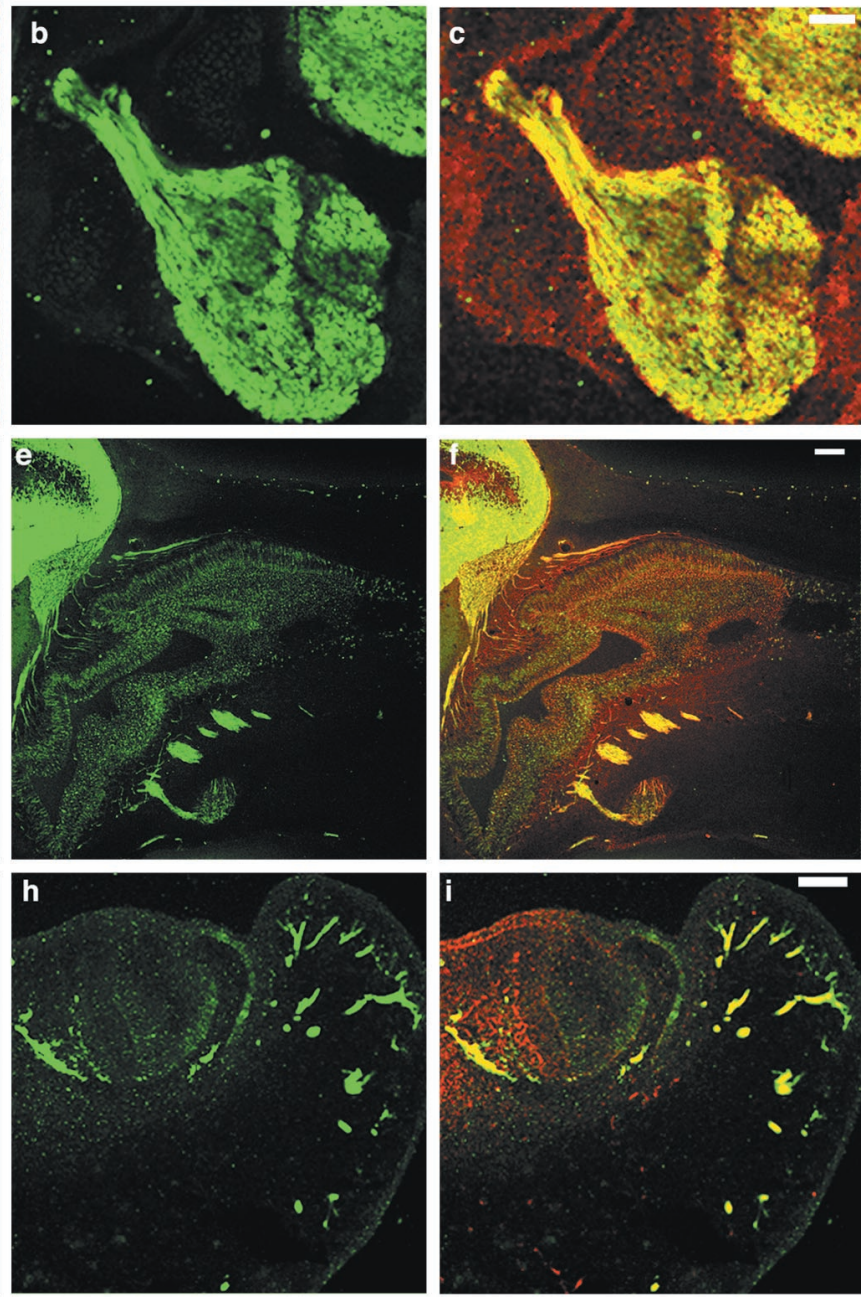

Figure 8. Doublecortin and phosphoFIGQY L1 CAMs colocalize in axon immunofluorescence of sections of rat tissue was performed with anti-phosphoFIGQY antibody and goat anti-doubleCAM $(a, d, g$, red $)$, doublecortin $(b, e, h$ green), and overlap $(c, f, i)$. $a-c$, Axon tracts in the dorsal root ganglion; overlap (c). $D C X$, Doublecortin; $D R G$, dorsal root ganglion; phospho-FIGQY, phospho-FIGQY L1 CAM. Scale bar, 100 $\mu \mathrm{m} . d-f$, Axon fascicle (arrows) in olfactory placode. $a x f$, Axon fascicle; $n b$, neuroblastoma; $o b$, developing olfactory bulb; op, olfactory placode; vno, vomeronasal organ. Scale bar, $100 \mu \mathrm{m} . g-i$, Axon fascicle (arrow) in the developing mandible. Scale bar, $50 \mu \mathrm{m}$.

structures did not show significant staining with the neurofascin antibody. This raises the possibility the doublecortin can interact with phospho-FIGQY L1 CAMs other than neurofascin. Cells in the bottom right-hand corner do not show phospho-FIGQY staining. These cells are in the striatal region that is close to the rostral migratory stream. Nacher et al. (2001) have described doublecortin immunoreactive cells with long processes reminiscent of putative migrating neurons. Differentiated neurons extending long processes into the striatum expressing doublecortin have also been identified (Nacher et al., 2001). It is unclear whether any of these cells are migrating neurons. The cells in the bottom righthand corner lacking the phospho-FIGQY L1 CAM but expressing doublecortin are likely to be such cells and might not be true migrating neurons.

SVZ explants were cultured in a three-dimensional extracellular matrix (Matrigel) (Wichterle et al., 1997). Under these conditions neurons migrate out from the explants using each other as a scaffold and form chain-like structures. Such explant cultures were stained for immunofluorescence with antibodies for $\beta$ III tubulin to identify postmitotic neurons, phospho-FIGQY L1 CAMs, and doublecortin (Fig. 7B). The differential interference contrast (DIC) image shows a characteristic chain-like structure formed by migrating cells (Fig. 7B, arrowhead, DIC). PhosphoFIGQY L1 CAMs (red) and doublecortin (green) are coexpressed within cells that are migrating in chain pattern from the explant. These cells also express $\beta$ III tubulin, indicating that they (Fig. 7B, $\beta$ III Tubulin) are neurons undergoing chain migration. We have thus demonstrated instances of overlapping expression of doublecortin with phospho-FIGQY neurofascin in migrating neurons in the embryonic brain and a phospho-FIGQY L1 CAM(s), the identity of which remains to be established in adult brain. In addition we have demonstrated the coexpression of phospho-FIGQY L1 CAMs with doublecortin in migrating neurons generated in vitro from subventricular zone explants.

Doublecortin and phospho-FIGQY-L1 CAMs also are coexpressed in developing axon tracts (Fig. 8). Double immunofluorescence demonstrates that phospho-FIGQY L1 CAMs (red, left panels) and doublecortin (green, middle panels) colocalize (yellow, right panels) in the axon fascicles in the dorsal root ganglion $(a-c)$, the axon tracts that extend into the developing olfactory bulb from the olfactory placode as well as the developing vomeronasal organ $(d-f)$, and the axon fascicles belonging to the intraalary group of sensory nerves in the lower mandible $(g-i)$. These results suggest that a complex between doublecortin and phospho-FIGQY L1 CAMs could exist in developing axons in addition to migrating neurons.

\section{DISCUSSION}

This study describes a new activity of doublecortin in recognition of the phospho-FIGQY tyrosine present in the cytoplasmic do- 
main of neurofascin, a member of the L1 family of cell adhesion molecules. Phospho-FIGQY-neurofascin (186 kDa) coimmunoprecipitated with doublecortin from detergent extracts of embryonic brain membranes, and this doublecortin-phospho-FIGQYneurofascin complex was disassociated by a synthetic phosphoFIGQY neurofascin peptide but not by a dephospho-FIGQY peptide. Doublecortin specifically recognized the phosphoFIGQY tyrosine in the context of a synthetic phospho-FIGQY neurofascin peptide and in phospho-FIGQY neurofascin isolated from cells treated with pervanadate. Mutations of doublecortin causing XLIS (R59H, D62N, and G253D) abolished binding to the phospho-FIGQY peptide and to phospho-FIGQY neurofascin. Finally, phospho-FIGQY neurofascin and doublecortin colocalize in developing axon tracts and in zones enriched in migrating neurons in the embryonic cerebral cortex. In the adult rostral migratory stream, doublecortin colocalizes in migrating neurons with a phospho-FIGQY bearing L1 CAM different from neurofascin.

These findings suggest the possibility that doublecortin functions as a phosphotyrosine adapter that serves as a link between neurofascin and other proteins that are capable of interacting with doublecortin. Candidate proteins to be coupled by doublecortin to phospho-FIGQY neurofascin include microtubules (Francis et al., 1999; Gleeson et al., 1999; Horesh et al., 1999), LIS1 (Caspi et al., 2000), and the $\mu$ subunit of AP-1 and AP-2 clathrin adapter complexes (Friocourt et al., 2001). Doublecortin associated with phospho-FIGQY neurofascin could potentially serve as a membrane tether for microtubules and LIS1. Doublecortin could play a role in the vesicular trafficking of phosphorylated neurofascin through its association with the AP-1 and AP-2 complexes, which are components of clathrin-coated vesicles.

The phospho-FIGQY motif-binding activity of doublecortin requires the contribution of the two domains in doublecortin. This is in contrast to $\mathrm{SH} 2$ and PTB domains, which are capable of independently binding phosphotyrosine motifs in various proteins. The doublecortin amino acid sequence does not show similarity to the amino acid sequence of SH2 domain or PTB domains that are found in the currently identified phosphotyrosine adapter proteins. Moreover, the stretch of amino acid residues encompassing the FIGQY motif shows little homology to peptides that bind to known $\mathrm{SH} 2$ or protein tyrosine binding domains, or to conventional substrates for protein tyrosine kinases (Scansite, http://scansite.mit.edu). Doublecortin could thus represent a new class of phosphotyrosine adapters with a novel sequence preference. Alternatively, the doublecortin-phosphoFIGQY interaction may be restricted to phospho-FIGQYtyrosine of neurofascin and possibly the other L1 CAMs.

L1 and NrCAM share an identical sequence with neurofascin up to the FIGQY tyrosine and have similar $\mathrm{COOH}$-terminal residues (SGKKE) that differ from the neurofascin sequence (TVRKD). The presence of the FIGQY motif in L1 and NrCAM raises the possibility that these L1 CAMs also can bind doublecortin when the FIGQY tyrosine is phosphorylated. However, neurofascin was the only L1 CAM that was enriched in immunoprecipitates of doublecortin from embryonic brain, although small amounts of L1 were also present. One possible explanation is that neurofascin is the major L1 CAM coexpressed with doublecortin during this developmental period, whereas at later times doublecortin is associated with other L1 CAMs. Further structural analysis of the sequence required for doublecortin binding should resolve this issue.
FIGQY phosphorylation of L1 CAMs has been demonstrated in the developing epithelium of the lung and midgut and neuromuscular junction in rat (Jenkins et al., 2001) and in epithelial tissues in C. elegans (Chen et al., 2001). This raises the possibility of the existence of proteins related to doublecortin that are capable of binding the phospho-FIGQY motif present in neurofascin and perhaps other L1 CAMs outside the nervous system. Five proteins with significant sequence similarity to doublecortin are present in the human genome. The most highly conserved gene, located on chromosome 13 , encodes proteins by alternative splicing that include a doublecortin-like protein and a doublecortin-protein kinase chimeric protein (DCLK, DC-13) (Burgess et al., 1999). DC-13 expression, however, is restricted to the developing nervous system. In support of a DC-13 interaction with phospho-FIGQY L1 CAMs, expression of doublecortin-13 gene products in the embryonic cortex occurs in the neuroepithelium and as well as the preplate and is similar to that of phospho-FIGQY L1 CAMs (Fig. 6) (Lin et al., 2000). Other genes encoding doublecortin-like proteins are present on chromosome 4 (GenBank Accession: NT 029954.3), chromosome 2 (GenBank Accession: NT 022139.7), chromosome 3 (GenBank Accession: NT 005580.8), and chromosome 8 (GenBank Accession: NT_008101.8). Many of the critical amino acid residues in doublecortin, which are mutated in XLIS, are conserved in these putative doublecortin-like proteins. The tissue specificity of expression of these putative doublecortin-like proteins is not currently known. In addition, $C$. elegans expresses a protein with a doubleocortin domain, a homolog of DC-13, termed zyg-8 (Gonczy et al., 2001). Zyg-8 is present in the C. elegans embryo at the two-cell stage, although expression in adult tissues remains to be evaluated.

This study is the first report of the expression of doublecortin in developing axon tracts outside the brain. Francis et al. (1999) have shown previously the expression of doublecortin in axons of differentiating neurons in the intermediate zone in the developing cortex. The intense expression of doublecortin in embryonic axon tracts suggests a function for this protein in these developing axon tracts in addition to its role in neuronal migration. Doublecortin has been shown to bind the $\mu$ subunit of the AP-1 and AP-2 clathrin adapter complexes (Friocourt et al., 2001). Doublecortin could function as a potential phosphotyrosine adapter between phospho-FIGQY neurofascin and the $\mu$ subunit of the clathrin adapter complexes on endocytic vesicles. This raises the possibility of a doublecortin-dependent pathway for the axonal transport of vesicles bearing FIGQY-phosphorylated neurofascin.

Doublecortin binds to LIS1, another protein involved in neuronal migration disorders (Caspi et al., 2000). LIS1 is thus a candidate protein that can be linked to the phospho-FIGQY neurofascin by doublecortin. Mutations in human LIS1 as in doublecortin result in neuronal migration defects in the cerebral cortex that manifest as lissencephaly (Vallee et al., 2001). LIS1 plays a critical role in nucleokinesis in Aspergillus (Xiang et al., 1995; Morris et al., 1998). Nucleokinesis is thought to be an important step in the act of neuronal migration. A LIS1-dynein microtubule motor complex is thought to attach to the cell cortex and generate the force necessary to move the nucleus (for review, see Vallee et al., 2001; Wynshaw-Boris and Gambello, 2001). The linkage between LIS1 and the cortex is unclear (Vallee et al., 2001). Doublecortin in its role as the FIGQY phosphotyrosine adapter could provide a cell cortex anchor point for LIS1 by linking it to phospho-FIGQY neurofascin. 


\section{REFERENCES}

Bieber AJ, Snow PM, Hortsch M, Patel NH, Jacobs JR, Traquina ZR, Schilling J, Goodman CS (1989) Drosophila neuroglian: a member of the immunoglobulin superfamily with extensive homology to the vertebrate neural adhesion molecule L1. Cell 59:447-460.

Brummendorf T, Kenwrick S, Rathjen FG (1998) Neural cell recognition molecule L1: from cell biology to human hereditary brain malformations. Curr Opin Neurobiol 8:87-97.

Burgess HA, Martinez S, Reiner O (1999) KIAA0369, doublecortin-like kinase, is expressed during brain development. J Neurosci Res $58: 567-575$.

Caspi M, Atlas R, Kantor A, Sapir T, Reiner O (2000) Interaction between LIS1 and doublecortin, two lissencephaly gene products. Hum Mol Genet 9:2205-2213.

Chen L, Ong B, Bennett V (2001) LAD-1, the Caenorhabditis elegans L1 CAM homologue, participates in embryonic and gonadal morphogenesis and is a substrate for fibroblast growth factor receptor pathwaydependent phosphotyrosine-based signaling. J Cell Biol 154:841-856.

Cohen NR, Taylor JS, Scott LB, Guillery RW, Soriano P, Furley AJ (1998) Errors in corticospinal axon guidance in mice lacking the neural cell adhesion molecule L1. Curr Biol 8:26-33.

Dahme M, Bartsch U, Martini R, Anliker B, Schachner M, Mantei N (1997) Disruption of the mouse L1 gene leads to malformations of the nervous system. Nat Genet 17:346-349.

Davis JQ, Bennett V (1993) Ankyrin-binding activity of nervous system cell adhesion molecules expressed in adult brain. J Cell Sci [Suppl] 17:109-117.

Davis JQ, Bennett V (1994) Ankyrin binding activity shared by the neurofascin/L1/NrCAM family of nervous system cell adhesion molecules. J Biol Chem 269:27163-27166.

Davis JQ, Lambert S, Bennett V (1996) Molecular composition of the node of Ranvier: identification of ankyrin-binding cell adhesion molecule neurofascin (mucin +/third FN111 domain) and NrCam at nodal axon segments. J Cell Biol 135:1355-1367.

Demyanenko GP, Tsai AY, Maness PF (1999) Abnormalities in neuronal process extension, hippocampal development, and the ventricular system of L1 knock-out mice. J Neurosci 19:4907-4920.

Demyanenko GP, Shibata Y, Maness PF (2001) Altered distribution of dopaminergic neurons in the brain of L1 null mice. Brain Res Dev Brain Res 126:21-30.

des Portes V, Francis F, Pinard JM, Desguerre I, Moutard ML, Snoeck I, Meiners LC, Capron F, Cusmai R, Ricci S, Motte J, Echenne B, Ponsot G, Dulac O, Chelly J, Beldjord C (1998a) Doublecortin is the major gene causing X-linked subcortical laminar heterotopia (SCLH). Hum Mol Genet 7:1063-1070.

des Portes V, Pinard JM, Billuart P, Vinet MC, Koulakoff A, Carrie A, Gelot A, Dupuis E, Motte J, Berwald-Netter Y, Catala M, Kahn A, Beldjord C, Chelly J (1998b) A novel CNS gene required for neuronal migration and involved in X-linked subcortical laminar heterotopia and lissencephaly syndrome. Cell 92:51-61.

Dubreuil RR, MacVicar G, Dissanayake S, Liu C, Homer D, Hortsch M (1996) Neuroglian-mediated cell adhesion induces assembly of the membrane skeleton at cell contact sites. J Cell Biol 133:647-655.

Francis F, Koulakoff A, Boucher D, Chafey P, Schaar B, Vinet MC, Friocourt G, McDonnell N, Reiner O, Kahn A, McConnell SK, Berwald-Netter Y, Denoulet P, Chelly J (1999) Doublecortin is a developmentally regulated, microtubule-associated protein expressed in migrating and differentiating neurons. Neuron 23:247-256.

Fransen E, Lemmon V, Van Camp G, Vits L, Coucke P, Willems PJ (1995) CRASH syndrome: clinical spectrum of corpus callosum hypoplasia, retardation, adducted thumbs, spastic paraparesis and hydrocephalus due to mutations in one single gene, L1. Eur J Hum Genet 3:273-284.

Fransen E, Van Camp G, D'Hooge R, Vits L, Willems PJ (1998) Genotype-phenotype correlation in L1 associated diseases. J Med Genet 35:399-404.

Friocourt G, Chafey P, Billuart P, Koulakoff A, Vinet MC, Schaar BT, McConnell SK, Francis F, Chelly J (2001) Doublecortin interacts with mu subunits of clathrin adaptor complexes in the developing nervous system. Mol Cell Neurosci 18:307-319.

Fukuda T, Kawano H, Ohyama K, Li HP, Takeda Y, Oohira A, Kawamura K (1997) Immunohistochemical localization of neurocan and L1 in the formation of thalamocortical pathway of developing rats. J Comp Neurol 382:141-152.

Garver TD, Ren Q, Tuvia S, Bennett V (1997) Tyrosine phosphorylation at a site highly conserved in the L1 family of cell adhesion molecules abolishes ankyrin binding and increases lateral mobility of neurofascin. J Cell Biol 137:703-714.

Gleeson JG, Allen KM, Fox JW, Lamperti ED, Berkovic S, Scheffer I, Cooper EC, Dobyns WB, Minnerath SR, Ross ME, Walsh CA (1998) Doublecortin, a brain-specific gene mutated in human X-linked lissencephaly and double cortex syndrome, encodes a putative signaling protein. Cell 92:63-72.

Gleeson JG, Lin PT, Flanagan LA, Walsh CA (1999) Doublecortin is a microtubule-associated protein and is expressed widely by migrating neurons. Neuron 23:257-271.

Gonczy P, Grill S, Stelzer EH, Kirkham M, Hyman AA (2001) Spindle positioning during the asymmetric first cell division of Caenorhabditis elegans embryos. Novartis Found Symp 237:164-175.

Horesh D, Sapir T, Francis F, Wolf SG, Caspi M, Elbaum M, Chelly J Reiner O (1999) Doublecortin, a stabilizer of microtubules. Hum Mol Genet 8:1599-1610.

Hortsch M (1996) The L1 family of neural cell adhesion molecules: old proteins performing new tricks. Neuron 17:587-593.

Hortsch M (2000) Structural and functional evolution of the L1 family: are four adhesion molecules better than one? Mol Cell Neurosci $15: 1-10$.

Jenkins SM, Kizhatil K, Kramarcy NR, Sen A, Sealock R, Bennett V (2001) FIGQY phosphorylation defines discrete populations of L1 cell adhesion molecules at sites of cell-cell contact and in migrating neurons. J Cell Sci 114:3823-3835.

Lee MK, Tuttle JB, Rebhun LI, Cleveland DW, Frankfurter A (1990) The expression and posttranslational modification of a neuron-specific beta-tubulin isotype during chick embryogenesis. Cell Motil Cytoskeleton $17: 118-132$

Lin PT, Gleeson JG, Corbo JC, Flanagan L, Walsh CA (2000) DCAMKL1 encodes a protein kinase with homology to doublecortin that regulates microtubule polymerization. J Neurosci 20:9152-9161.

Lois C, Alvarez-Buylla A (1994) Long-distance neuronal migration in the adult mammalian brain. Science 264:1145-1148.

Lois C, Garcia-Verdugo JM, Alvarez-Buylla A (1996) Chain migration of neuronal precursors. Science 271:978-981.

Morris NR, Efimov VP, Xiang X (1998) Nuclear migration, nucleokinesis and lissencephaly. Trends Cell Biol 8:467-470.

Nacher J, Crespo C, McEwen BS (2001) Doublecortin expression in the adult rat telencephalon. Eur J Neurosci 14:629-644.

Needham LK, Thelen K, Maness PF (2001) Cytoplasmic domain mutations of the L1 cell adhesion molecule reduce L1-ankyrin interactions. J Neurosci 21:1490-1500.

Sapir T, Elbaum M, Reiner O (1997) Reduction of microtubule catastrophe events by LIS1, platelet-activating factor acetylhydrolase subunit. EMBO J 16:6977-6984.

Sapir T, Horesh D, Caspi M, Atlas R, Burgess HA, Wolf SG, Francis F, Chelly J, Elbaum M, Pietrokovski S, Reiner O (2000) Doublecortin mutations cluster in evolutionarily conserved functional domains. Hum Mol Genet 9:703-712.

Taylor KR, Holzer AK, Bazan JF, Walsh CA, Gleeson JG (2000) Patient mutations in doublecortin define a repeated tubulin-binding domain. J Biol Chem 275:34442-34450.

Tuvia S, Garver TD, Bennett V (1997) The phosphorylation state of the FIGQY tyrosine of neurofascin determines ankyrin-binding activity and patterns of cell segregation. Proc Natl Acad Sci USA 94:12957-12962.

Vallee RB, Tai C, Faulkner NE (2001) LIS1: cellular function of a disease-causing gene. Trends Cell Biol 11:155-160.

Wichterle H, Garcia-Verdugo JM, Alvarez-Buylla A (1997) Direct evidence for homotypic, glia-independent neuronal migration. Neuron 18:779-791.

Wynshaw-Boris A, Gambello MJ (2001) LIS1 and dynein motor function in neuronal migration and development. Genes Dev 15:639-651.

Xiang X, Osmani AH, Osmani SA, Xin M, Morris NR (1995) NudF, a nuclear migration gene in Aspergillus nidulans, is similar to the human LIS-1 gene required for neuronal migration. Mol Biol Cell 6:297-310.

Zhang X, Davis JQ, Carpenter S, Bennett V (1998) Structural requirements for association of neurofascin with ankyrin. J Biol Chem 273: 30785-30794. 